University of New Mexico

UNM Digital Repository

5-1-2005

\title{
A dimensionless invariant for relative size at sex change in animals: Explanation and implications
}

Andy Gardner

David Allsop

Eric Charnov

Stuart West

Follow this and additional works at: https://digitalrepository.unm.edu/biol_fsp

Part of the Biology Commons

\section{Recommended Citation}

Gardner, A., D.J. Allsop, E.L. Charnov and S.A. West. 2005. A dimensionless invariant for relative size at sex change in animals: Explanation and implications. American Naturalist 165:551-566

This Article is brought to you for free and open access by the Academic Department Resources at UNM Digital Repository. It has been accepted for inclusion in Biology Faculty \& Staff Publications by an authorized administrator of UNM Digital Repository. For more information, please contact disc@unm.edu. 


\title{
A Dimensionless Invariant for Relative Size at Sex Change in Animals: Explanation and Implications
}

\author{
Andy Gardner, ${ }^{1,2, \star}$ David J. Allsop, ${ }^{1,3, \uparrow}$ Eric L. Charnov, ${ }^{4, \star}$ and Stuart A. West ${ }^{1, \$}$
}

1. Institute of Evolutionary Biology, University of Edinburgh, Edinburgh EH9 3JT, United Kingdom;

2. Department of Mathematics and Statistics and Department of Biology, Queen's University, Kingston, Ontario, K7L 3N6, Canada; 3. School of Biological Sciences, University of Sydney, Sydney, New South Wales 2006, Australia;

4. Department of Biology, University of New Mexico, Albuquerque, New Mexico 87131; and Department of Fisheries and Wildlife, Oregon State University, Corvallis, Oregon 97331

Submitted September 1, 2004; Accepted December 16, 2004; Electronically published March 14, 2005

Online enhancement: table.

ABSTRACT: Recent comparative studies across sex-changing animals have found that the relative size and age at sex change are strikingly invariant. In particular, $91 \%-97 \%$ of the variation in size at sex change across species can be explained by the simple rule that individuals change sex when they reach $72 \%$ of their maximum body size. However, this degree of invariance is surprising and has proved controversial. In particular, it is not clear why this result should hold, given that there is considerable biological variation across species in factors that can influence the evolutionarily stable timing of sex change. Our overall aim here is to explain this result and determine the implications for other life-history variables. Specifically, we use a combination of approaches to formalize and make explicit previous analytical theory in this area, examine the robustness of the empirical invariance result, and carry out sensitivity analyses to determine what the empirical data imply about the mean value and variation in several key life-history variables.

Keywords: life history, sex allocation, protandry, protogyny, sequential hermaphroditism, Buckingham's $\pi$ theorem.

\footnotetext{
* Corresponding author; e-mail: andy.gardner@ed.ac.uk.

† E-mail: david.allsop@bio.usyd.edu.au.

₹ E-mail: rlc@unm.edu.

`E-mail: stu.west@ed.ac.uk.
}

Am. Nat. 2005. Vol. 165, pp. 551-566. (C) 2005 by The University of Chicago. 0003-0147/2005/16505-40602\$15.00. All rights reserved.
Sex change occurs in a variety of animals, including fish, echinoderms, crustaceans, mollusks, and polychaete worms (Charnov 1982b; Policansky 1982; Allsop and West $2004 b$ ). Evolutionary theory suggests that sex change is favored when the reproductive success varies with age or size and the relationship differs between the sexes. In this case, selection favors a strategy where individuals start as the sex whose fitness increases more slowly with age and then change to the other sex at a later stage (Ghiselin 1969; Leigh et al. 1976; Charnov 1982b; Warner 1988a, 1988b). Despite considerable differences in details across species, this basic idea is well established and has been widely applied to numerous animals and plants.

A recent development in the field of sex change has involved a dimensionless approach. Charnov and Skúladóttir (2000) pointed out that predictions for the evolutionarily stable (Maynard Smith and Price 1973) size or age at sex change could be expressed in terms of several dimensionless quantities. Their results depend upon the von Bertalanffy (1938) growth coefficient $(k)$, the adult instantaneous mortality rate $(M)$, the age at first breeding $(\alpha)$, and the exponent $(\delta)$ relating male size to fecundity (according to the power law, fecundity $\propto$ size $^{\delta}$ ); definitions of key notation are given in table 1. Specifically, the dimensionless values $k / M, \alpha M$, and $\delta$ are of interest. Charnov and Skúladóttir (2000) showed that populations/species with the same values of these dimensionless quantities are predicted to have the same relative size at sex change, given by size at sex change/maximum size $\left(L_{50} / L_{\max }\right)$; the same relative age at sex change, given by age at sex change/age at first breeding $(\tau / \alpha)$; and the same breeding sex ratio, defined as the proportion of breeders that are male. Several studies have suggested that $\alpha M$ and $k / M$ can be invariant within and even across taxa (Charnov 1993; Gemmill et al. 1999). Consequently, invariant relative size and age at sex change are predicted whenever $\delta$ is also invariant.

It could be expected that $\delta$ would be roughly invariant within species or across closely related species sharing a similar life history. Consistent with this, an invariant relative size at sex change has been observed across popu- 
Table 1: Key notation used in this article

\begin{tabular}{ll}
\hline Symbol & \\
\hline$\alpha$ & Age at maturity \\
$\tau$ & Age at sex change \\
$\tau_{\mathrm{v}}$ & Variant age at sex change \\
$\tau_{\mathrm{r}}$ & Resident age at sex change \\
$\tau^{*}$ & Evolutionarily stable strategy age at sex change \\
$k$ & von Bertalanffy growth coefficient \\
$M$ & Instantaneous adult mortality rate \\
$\delta, \delta_{\text {male }}$ & Male fecundity exponent \\
$\delta_{\text {female }}$ & Female fecundity exponent \\
$\delta_{1}, \delta_{2}$ & Fecundity exponent for first and second sex \\
$L$ & Size (body length) \\
$L_{\text {mat }}$ & Size at maturity (smallest observed adult) \\
$L_{50}$ & Size at sex change (50\% of individuals have changed sex) \\
$L_{\text {max }}$ & Maximum size (largest observed individual) \\
$V$ & Reproductive value \\
$V_{1}, V_{2}$ & Class reproductive values for first and second sexes \\
$\lambda$ & Asymptotic rate of increase of rare variant sex change strategy \\
$w$ & Fitness, that which is maximized by selection \\
$S_{1}, S_{2}$ & Reproductive success through functioning as first and second sex \\
$p$ & Probability of survival \\
$Q_{1}, Q_{2}$ & Instantaneous reproductive rate for first and second sex \\
$N_{1}, N_{2}$ & Number of breeders of first and second sex \\
$N_{\text {male }}, N_{\text {female }}$ & Number of breeding males and breeding females \\
$F$ & Proportion of females among breeders \\
$\sigma, \sigma_{X}$ & Standard deviation, standard deviation of $X$ \\
$U\left[z_{\min }, z_{\text {max }}\right]$ & Continuous uniform distribution over interval $z_{\min }$ to $z_{\text {max }}$ \\
\hline &
\end{tabular}

lations of the shrimp Pandalus borealis in the waters off Iceland (Skúladóttir and Petursson 1999; Charnov and Skúladóttir 2000). However, the invariant relationship also holds across species. The relative size and age at sex change have been found to be invariant across fish species (Allsop and West 2003b) and even across all sex-changing animals (including data from 77 species of fish, echinoderms, crustaceans, and mollusks; Allsop and West 2003a). Specifically, $91 \%-97 \%$ of the variation in size at sex change across species can be explained by the rule that species change sex at $72 \%$ of their maximum size. This result holds despite huge variation in size and mating system across species, from a $2-\mathrm{mm}$ crustacean to a $1.5-\mathrm{m}$ fish (fig. 1).

This extent of invariance in the relative size at sex change across species was relatively surprising and has proved controversial (Allsop and West 2004a; Buston et al. 2004; Millius 2004). The main reason for this is that there is considerable variation across species in factors that could influence the evolutionarily stable timing of sex change, particularly the following: First, sex change is from male to female (protandrous) in some species, female to male (protogynous) in others, and even in both directions in some (Nakashima et al. 1995). Given that female fertility is likely to be proportional to body size cubed $\left(L^{3}\right.$; Charnov 1979, 1993), for sex change to be favored there must be variation in $\delta$ between protandrous $(\delta<3)$ and protogynous $(\delta>3)$ species. Second, in some species there is a fraction of individuals who mature early as the second sex, which is likely to correlate with or cause variation in $\delta$ (Charnov 1982a, 1982b; Warner 1984; Allsop and West $2004 b, 2004 c)$. Third, there is huge variation in mating system across species, which could translate into variation in $\delta$. For example, within just the fish species, the range of mating systems includes harems, leks, monandry, and aggregation spawners (Warner 1984; Allsop and West $2003 \mathrm{~b}$ ). Fourth, the cues and mechanisms involved in sex change vary across species, depending on factors such as social environment, size, and parasitism (Shapiro 1980, 1981; Shapiro and Lubbock 1980; Scharer and Vizoso 2003). Fifth, while $\alpha M$ is likely to be invariant across all sex changers, with a value of approximately 2 , it unclear whether $k / M$ is similarly invariant (Charnov and Berrigan 1990; Charnov 1993; Gemmill et al. 1999).

Our overall aim here is to determine both how the invariant results can hold in the face of so much biological variation across species and what the implications for other life-history variables are. Our article is divided into three sections. In the first section, we test the underlying generality of the sex change invariant predictions. Specifically, we provide a more explicit proof of Charnov and Skúla- 


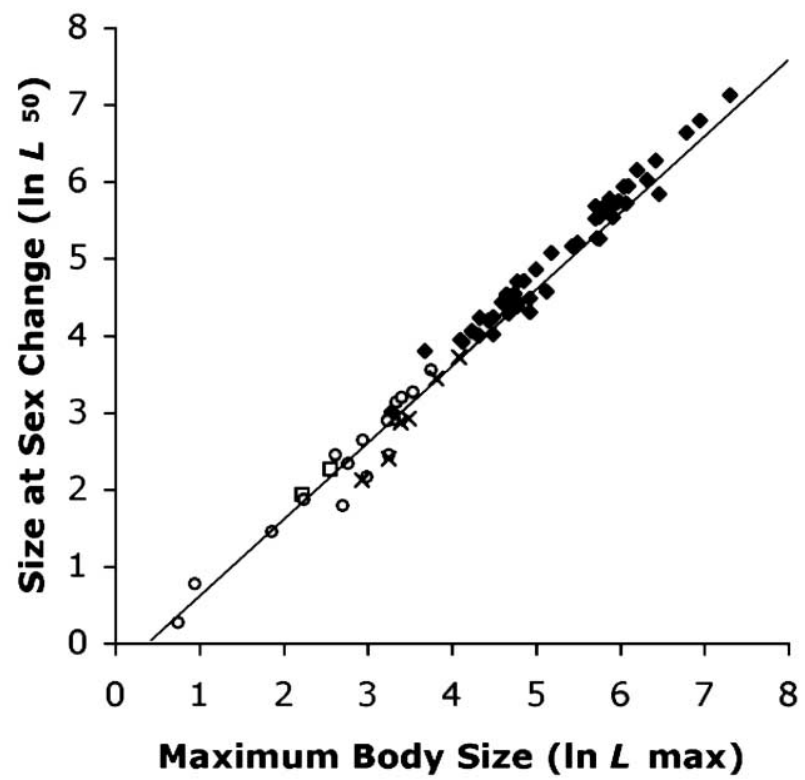

Figure 1: Log-log plot of $L_{50}$ versus $L_{\max }$ for 77 species of sex-changing animals with species as independent data points. Data are split by taxa: Echinodermata (asterisks), Crustacea (circles), Chordata (diamonds), and Mollusca (crosses). The regression has a slope fixed at 1, giving an intercept of $-0.32 \pm 0.05$ (95\% confidence interval [CI]) and $r^{2}=0.97$. The ordinary least squares slope is $1.05 \pm 0.03$ (95\% CI), with an intercept of $-0.55 \pm 0.07(95 \% \mathrm{CI})$ and $r^{2}=0.98$. The mean relative size at sex change $\left(L_{50} / L_{\max }\right)$ is $0.72(95 \% \mathrm{CI}=0.67-0.77)$, implying that individuals change sex when they reach $72 \%$ of their maximum size. Size $\left(L_{50}\right.$ and $\left.L_{\max }\right)$ is measured in millimeters before logarithmic transformation.

dóttir's (2000) invariant predictions and show that the sex change invariants can also be predicted by an alternative modeling approach, assuming that sex change occurs in response to social environment, as is known to occur in some fish (Shapiro 1981; Warner and Swearer 1991; Allsop and West $2004 c$ ), rather than in response to age or size, as assumed by Charnov and Skúladóttir.

In the second section, we examine the statistical significance of Allsop and West's (2003a, 2003b) empirical result showing that the relative size at sex change is invariant. Buston et al. (2004; Millius 2004) have criticized Allsop and West's analysis and have argued that an alternative null model approach based upon randomization techniques does not support the invariant prediction. We assess the validity of Buston et al.'s analysis and develop and test a more appropriate null model. This section quantifies and expands on some issues we have raised in a previous short comment (Allsop and West 2004a).

In the third section, we carry out a sensitivity analysis of the Charnov-Skúladóttir model to test how variation in the key life-history parameters $(\alpha M, k / M$, and $\delta)$ influences the predicted relationship between size at sex change and maximum size. Specifically, we use the existing information on $\alpha M, k / M$, and the relative size at sex change to estimate $\delta$; estimate how variation in $\alpha M, k / M$, and $\delta$ influences the extent and nature of the relative size at sex change invariant that would be expected; and estimate the amount of variation in $\alpha M$ and $k / M$ that is consistent with the empirical data.

\section{When Is an Invariant Relative Size at Sex Change Expected? \\ Formalizing Charnov and Skúladóttir's Invariant Predictions}

The model of Charnov and Skúladóttir (2000) makes use of the observation that selection acts as if to maximize the product of reproductive success through male and female function (MacArthur 1965; Charnov 1979, 1982b). The following argument for the product maximand is phrased in terms of sex change, although it applies to sex allocation in general. Consider a vanishingly rare sex change variant, which changes sex at age $\tau_{v}$, within a population with resident strategy $\tau_{\mathrm{r}}$. Assuming panmixia, reproductive value $(V)$ is reproductive success as the first sex $\left(S_{1}\right)$ plus reproductive success as the second sex $\left(S_{2}\right)$, each weighted by the class reproductive value for the appropriate $\operatorname{sex}\left(V_{1}\right.$ and $\left.V_{2}\right)$ :

$$
V\left(\tau_{\mathrm{v}}, \tau_{\mathrm{r}}\right)=S_{1}\left(\tau_{\mathrm{v}}\right) V_{1}+S_{2}\left(\tau_{\mathrm{v}}\right) V_{2}
$$

Since total reproductive values of males is equal to that of females (Fisher 1930), then $S_{1}\left(\tau_{\mathrm{r}}\right) V_{1}=S_{2}\left(\tau_{\mathrm{r}}\right) V_{2}$, and hence $V_{1}=\left(S_{2}\left(\tau_{\mathrm{r}}\right) / S_{1}\left(\tau_{\mathrm{r}}\right)\right) V_{2}$. Substituting into equation (1) and dividing by the reproductive value of the resident strategy yields the variant's asymptotic rate of increase:

$$
\lambda\left(\tau_{\mathrm{v}}, \tau_{\mathrm{r}}\right)=\frac{V\left(\tau_{\mathrm{v}}, \tau_{\mathrm{r}}\right)}{V\left(\tau_{\mathrm{r}}, \tau_{\mathrm{r}}\right)}=\frac{1}{2}\left(\frac{S_{1}\left(\tau_{\mathrm{v}}\right)}{S_{1}\left(\tau_{\mathrm{r}}\right)}+\frac{S_{2}\left(\tau_{\mathrm{v}}\right)}{S_{2}\left(\tau_{\mathrm{r}}\right)}\right) .
$$

Here $\lambda>1$ indicates that the variant invades. The local evolutionarily stable strategy (ESS; $\tau^{*}$ ) satisfies $d \lambda /\left.d \tau_{\mathrm{v}}\right|_{\tau_{\mathrm{v}}=\tau_{\mathrm{r}}=\tau=\tau *}=0$; that is, it is a solution to

$$
\frac{S_{1}^{\prime}(\tau)}{S_{1}(\tau)}+\frac{S_{2}^{\prime}(\tau)}{S_{2}(\tau)}=0
$$

(Shaw and Mohler 1953; Charnov 1979, 1982b). Assuming convergence stability (Christiansen 1991), $\tau^{*}$ is the strategy that maximizes the integral of the left-hand side of equation (3) with respect to $\tau$, 


$$
\int\left(\frac{S_{1}^{\prime}(\tau)}{S_{1}(\tau)}+\frac{S_{2}^{\prime}(\tau)}{S_{2}(\tau)}\right) d \tau=S_{1}(\tau) S_{2}(\tau)+\text { constant }
$$

(Charnov 1979, 1982b; de Valpine 2000). Defining fitness $(w)$ as that which is maximized by selection, an appropriate fitness function is then

$$
w(\tau)=S_{1}(\tau) S_{2}(\tau)
$$

that is, fitness is given by the product of reproductive success gained through each sex (MacArthur 1965; Charnov 1979, 1982b). Reproductive success as the first sex is given by integrating, over all ages $(x)$ from maturity (at age $\alpha$ ) to sex change (at age $\tau$ ), the product of instantaneous reproductive rate $\left(Q_{1}\right)$ and the probability $(p)$ of surviving to age $x$ :

$$
S_{1}=\int_{\alpha}^{\tau} p(x) Q_{1}(x) d x
$$

Following Charnov and Skúladóttir (2000), we assume first, a fixed instantaneous adult mortality rate $(M)$, such that the probability of survival takes the form $p(x)=$ $A e^{-M x}$, where $A$ is a constant; second, that instantaneous reproductive rate takes the form of a power law $Q_{1}(x)=B_{1} L(x)^{\delta_{1}}$, where $L(x)$ is size at age $x, B_{1}$ is a constant, and $\delta_{1}$ is the exponent appropriate for the first sex; and third, that size is related to age according to the von Bertalanffy (1938) function $L(x)=L_{\max }\left(1-e^{-k x}\right)$, where $L_{\max }$ is the maximum size of the species and $k$ is the von Bertalanffy growth coefficient. This equation has been used successfully to model growth of indeterminate growers (Beverton 1963, 1992; Pauly 1980). Hence,

$$
S_{1}=A B_{1} L_{\max }^{\delta_{1}} \int_{\alpha}^{\tau} e^{-M x}\left(1-e^{-k x}\right)^{\delta_{1}} d x
$$

For the second sex, with fecundity given by the power law $Q_{2}(x)=B_{2} L(x)^{\delta 2}$, we have

$$
S_{2}=A B_{2} L_{\max }^{\delta_{2}} \int_{\tau}^{\infty} e^{-M x}\left(1-e^{-k x}\right)^{\delta_{2}} d x
$$

Hence, fitness may be written as an explicit function of the age at sex change $(\tau)$ :

$$
w \propto\left[\int_{\alpha}^{\tau} e^{-M x}\left(1-e^{-k x}\right)^{\delta_{1}} d x\right] \times\left[\int_{\tau}^{\infty} e^{-M x}\left(1-e^{-k x}\right)^{\delta_{2}} d x\right]
$$

(Charnov and Skúladóttir 2000). The sex with the larger power-law exponent has the greater relative improvement in reproductive rate as the individual grows, and so fitness is maximized by reproducing as this sex when large and as the other sex when small. Sex change should therefore be in the direction of increasing power-law exponent; that is, $\delta_{1}<\delta_{2}$ (Warner et al. 1975; Leigh et al. 1976). For indeterminate growers, female fecundity scales approximately with size cubed $\left(\delta_{\text {female }} \approx 3\right.$; references in Charnov $1979,1993)$, so we may set $\delta_{\text {female }}=3$ and $\delta_{\text {male }}=\delta$. Thus, sex change is predicted to be male to female (protandry) when $\delta<3$ and female to male (protogyny) when $\delta>3$. Hence, fitness is

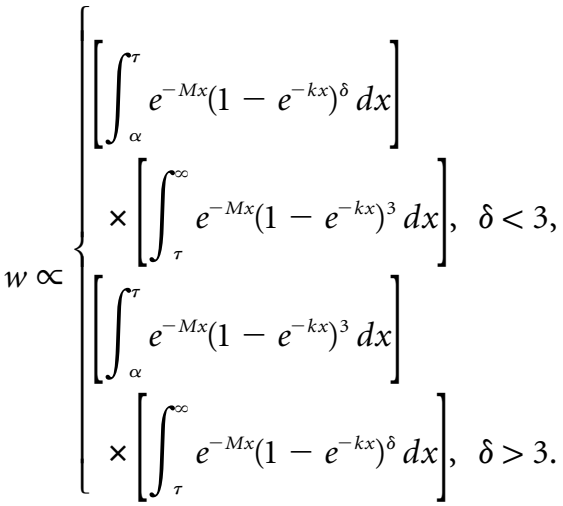

Charnov and Skúladóttir (2000) applied Buckingham's (1914; Stephens and Dunbar 1993) $\pi$ theorem to reveal that the fitness function (eq. [10]) could, in principle, be rewritten as a function of constants and the dimensionless life-history parameters $\tau / \alpha, \alpha M, k / M$, and $\delta$. The values $\tau / \alpha, \alpha M, k / M$, and $\delta$ are all dimensionless because $\tau$ and $\alpha$ have dimensions of time, $k$ and $M$ have dimensions of inverse time, and $\delta$ is an exponent in a power function. Being able to express fitness in this way indicates that the fitness function (eq. [10]) is invariant for circumstances where $\tau / \alpha, \alpha M, k / M$, and $\delta$ are invariant. Hence, fitness is maximized at the same relative age at sex change $\left(\tau / \alpha=\tau^{*} / \alpha\right)$ in all contexts where the other values $(\alpha M$, $k / M$, and $\delta$ ) are invariant.

We now derive an explicit fitness function in terms of dimensionless quantities, using the standard technique of switching variables. We make the substitution $x \rightarrow c y$ : where we see $x$ in the fitness function, we will write $c y$. The limits of the integrals need to be changed. For instance, the lower bound of the first integral is $x=\alpha$; hence, switching variables gives $y=\alpha / c$. Finally, $d x / d y=c$, so $d x=c d y$. This gives us 


$$
w \propto\left\{\begin{array}{l}
{\left[\int_{\alpha / c}^{\tau / c} e^{-M c y}\left(1-e^{-k c y}\right)^{\delta} d y\right]} \\
\times\left[\int_{\tau / c}^{\infty} e^{-M c y}\left(1-e^{-k c y}\right)^{3} d y\right], \delta<3, \\
{\left[\int_{\alpha / c}^{\tau / c} e^{-M c y}\left(1-e^{-k c y}\right)^{3} d y\right]} \\
\times\left[\int_{\tau / c}^{\infty} e^{-M c y}\left(1-e^{-k c y}\right)^{\delta} d y\right], \quad \delta>3 .
\end{array}\right.
$$

The constant $c$ is arbitrary, so we may set $c=\alpha$. Substituting and rearranging, we have

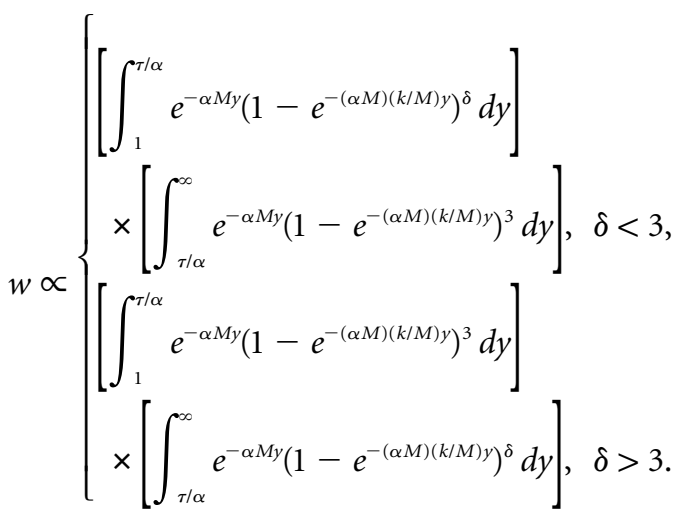

This is the fitness function Charnov and Skúladóttir predicted but did not find an explicit expression for. If the integrands in equation (12) are invariant (i.e., $\alpha M, k / M$, and $\delta$ are invariant), then fitness will be maximized by a relative age at sex change $\left(\tau^{*} / \alpha\right)$ that is invariant. Under these circumstances, we also predict further invariants. The size at sex change $\left(L_{50}\right)$ is given by $L\left(\tau^{*}\right)=L_{\max }[1-$ $\left.\exp \left(-k \tau^{*}\right)\right]$. Since $k \tau^{*}=\alpha M \times k / M \times \tau^{*} / \alpha$ is invariant, the size at sex change relative to maximum size $\left(L_{50} / L_{\max }\right)$ is predicted to be invariant (Charnov and Skúladóttir 2000). The relative size at maturity, $L_{\operatorname{mat}} / L_{\max }=$ $1-\exp (-\alpha k)$, is also expected to be invariant, since $\alpha k=\alpha M \times k / M$ is invariant. Finally, the ratio of breeders of the first sex $\left(N_{1}\right)$ to those of the second sex $\left(N_{2}\right)$ is

$$
\frac{N_{1}}{N_{2}}=\frac{\int_{\alpha}^{\tau^{*}} e^{-M x} d x}{\int_{\tau^{*}}^{\infty} e^{-M x} d x}=\frac{e^{-M \alpha}}{e^{-M \tau^{*}}}-1=\frac{e^{-\alpha M}}{e^{-(\alpha M)\left(\tau^{*} / \alpha\right)}}-1
$$

which, for invariant $\alpha M, k / M$, and $\delta$ (and hence invariant $\left.\tau^{*} / \alpha\right)$, is also invariant.

\section{Sex Change Invariant Predicted by an Alternative Approach}

The Charnov-Skúladóttir model assumes that timing of sex change is determined by size or age. However, it has been shown in numerous fish species that sex change can be stimulated by the social environment (Robertson 1972; Shapiro 1981; Warner and Swearer 1991; Allsop and West 2004c). For example, in the cleaner fish Labroides dimidiatus, the largest females change sex to become male harem holders upon removal of the male from the social group (Robertson 1972). Here we consider the situation where social environment is assumed to be the primary determinant of when sex change occurs. Specifically, we model a protogynous species in which females change sex to male to maintain a constant sex ratio, following Shapiro and Lubbock (1980). This means that our model has Charnov and Skúladóttir's (2000) third invariant prediction (constant breeding sex ratio) as its underlying starting assumption. Even though this represents essentially the extreme opposite mechanism underlying sex change to that assumed by the Charnov-Skúladóttir model, we are also able to predict the first two invariant predictions of that model, concerning the relative size and age at sex change.

Consider a protogynous species in which the largest (oldest) males each have harems of $F$ females. The largest female is selected to change sex when the ratio of breeding females to breeding males $\left(N_{\text {female }} / N_{\text {male }}\right)$ in the population is greater than $F$, and so the breeding sex ratio will be invariant and equal to $F$. This breeding sex ratio will be given as

$$
\frac{N_{\text {female }}}{N_{\text {male }}}=\frac{\int_{\alpha}^{\tau^{*}} e^{-M x} d x}{\int_{\tau^{*}}^{\infty} e^{-M x} d x}=\frac{e^{-\alpha M}}{e^{-\tau^{*} M}}-1=F .
$$

The value of $\alpha M$ is known to be invariant within taxa (Charnov and Berrigan 1990, 1991; Gemmill et al. 1999), and so for equation (14) to hold, $\tau^{*} M$ must also be invariant. Since $k / M$ is known to be invariant within taxa (Charnov 1993), the product $\tau^{*} M \times k / M=k \tau^{*}$ is an invariant. Applying the von Bertalanffy growth equation, the relative size at sex change $\left(L_{50} / L_{\max }=1-\exp \left[-k \tau^{*}\right]\right)$ is predicted to be invariant, giving the first of Charnov and Skúladóttir's invariance predictions. Dividing $\tau^{*} M$ by $\alpha M$ yields an invariant relative age at sex change $\tau^{*} / \alpha$, which is the second of Charnov and Skúladóttir's invariance predictions.

\section{Is the Relative Size at Sex Change Invariant across Species?}

Allsop and West $(2003 a, 2003 b)$ tested for invariance by using the standard methodology of whether a log-log plot 
Table 2: Empirical values for the RSSC derived from log-log regressions of the size at sex change against the maximum size with the slope fixed at proportionality (i.e., 1)

\begin{tabular}{|c|c|c|c|c|c|c|}
\hline \multirow[b]{3}{*}{ Taxa } & \multicolumn{6}{|c|}{ Direction of sex change } \\
\hline & \multicolumn{2}{|c|}{ Both directions } & \multicolumn{2}{|c|}{ Male first } & \multicolumn{2}{|c|}{ Female first } \\
\hline & Intercept & RSSC & Intercept & RSSC & Intercept & RSSC \\
\hline Arthropoda (crustaceans) & $-.42 \pm .12$ & $.66 \pm .08$ & $-.44 \pm .12$ & $.64 \pm .09$ & & \\
\hline Chordata (fish) & $-.26 \pm .04$ & $.77 \pm .03$ & $-.29 \pm .11$ & $.75 \pm .09$ & $-.25 \pm .04$ & $.78 \pm .03$ \\
\hline Mollusca & $-.57 \pm .16$ & $.57 \pm .10$ & $-.57 \pm .16$ & $.57 \pm .10$ & & \\
\hline Echinodermata & $-.32 \pm .05$ & $.73 \pm .03$ & $-.32 \pm .05$ & $.73 \pm .03$ & & \\
\hline
\end{tabular}

Note: The intercept for the regression is also given in the table. Entries include the $95 \%$ confidence interval. Data are split by taxa and direction of sex change. Empty cells represent instances when there are too few data points to perform the regressions for these categories alone. Data were obtained from Allsop and West $(2003 a, 2003 b)$. RSSC $=$ relative size at sex change $=L_{50} / L_{\max } . L_{50}=$ size at sex change; $L_{\max }=$ maximum size.

gave a slope not significantly different from unity (Harvey and Pagel 1991; Charnov 1993; Brown et al. 2000). In particular, they tested for an invariant relative size at sex change, by examining the relationship between the logarithms of mean size at sex change and maximum size across all sex-changing taxa (Allsop and West 2003a, 2003 ; fig. 1), and for an invariant relative age at sex change, by examining the relationship between the logarithms of mean age at sex change and mean age at maturity for sex-changing fish (Allsop and West 2003b). In these analyses a significant positive relationship between maximum size (age at maturity) and size (age) at sex change is not surprising, and it merely reflects that larger species change sex when bigger-the crucial point is determining the extent of variance in the relative size at sex change (Allsop and West 2003a, 2003b; table 2).

Buston et al. (2004; Millius 2004) criticized this approach and instead suggested the use of a null model based on randomization techniques. Specifically, they generated data for each species by randomly assigning a maximum body size, and (assuming that maturity is at 50\% of maximum body size) they then randomly assigned a size at sex change between $50 \%$ and $100 \%$ of maximum body size $\left(L_{\operatorname{mat}} / L_{\max }=0.5, L_{50} / L_{\max } \approx U[0.5,1]\right)$. This analysis generated data that gave slopes similar to those for the real data when the relation between the logarithms of size at sex change and maximum size were examined. Consequently, Buston et al. suggested that Allsop and West's invariant result was in fact nonsignificant.

However, the Buston et al. model can be rejected both empirically and because it is not a true null model. First, empirically, the Buston et al. model cannot produce the observed sex change data, because five of the 77 species in the data set (Allsop and West 2003a) change sex below their lower limit of $50 \%$ of the maximum body size (crustaceans Acontiostoma marionis, Ichthyoxenus fushanenensis, and Emerita analoga and gastropods Crepidula adunca and Crepidula linulata). Second, the distribution of relative size at sex change in the actual data is significantly different from the uniform distribution Buston et al. assume (Allsop and West 2004a). Third, Buston et al. arbitrarily assigned the size at maturity a value that forces a good fit between the model and the data (Allsop and West 2004a). Because the size at maturity is set to $50 \%$ and size at sex change is uniformly distributed over the range between maturity and maximum size, the model predicts an average relative size at sex change of $75 \%$, which is very close to the observed $72 \%$. However, previous work has suggested that a more accurate average size at maturity is $65 \%$ (Charnov 1993), which would give a mean size at sex change of $83 \%$, which is far from the observed data. Fourth, the assumption of a uniform distribution in relative size at sex change assumes no selection on size at sex change, which has been shown not to be the case in numerous studies over the past 35 years (Warner et al. 1975; Charnov et al. 1978; Charnov 1982b).

Furthermore, and more fundamentally, the Buston et al. model is not null, because it assumes an invariant relative size at maturity, which is linked to an invariant relative size at sex change in the Charnov-Skúladóttir model. An invariant relative size at maturity follows from two of the three dimensionless invariants required by the invariant sex change predictions, $\alpha M$ and $k / M$. If these are invariant, then their product $\alpha k$ is invariant, and so the relative size at maturity $\left(L_{\operatorname{mat}} / L_{\max }=1-\exp [-\alpha k]\right)$ is also invariant. We show in "Sensitivity Analysis" that these are the crucial invariants for the Charnov-Skúladóttir model ( $\delta$ is less important), so we would expect the Buston et al. null model to produce an invariant relative size at sex change and hence to fit the empirical data.

If an invariant relative size at maturity is not assumed, then more appropriate null models can be developed. The predictions of these differ significantly from the observed data. We examine a model in which maturation size is uniformly distributed from size zero to maximum size and size at sex change uniformly distributed from size 

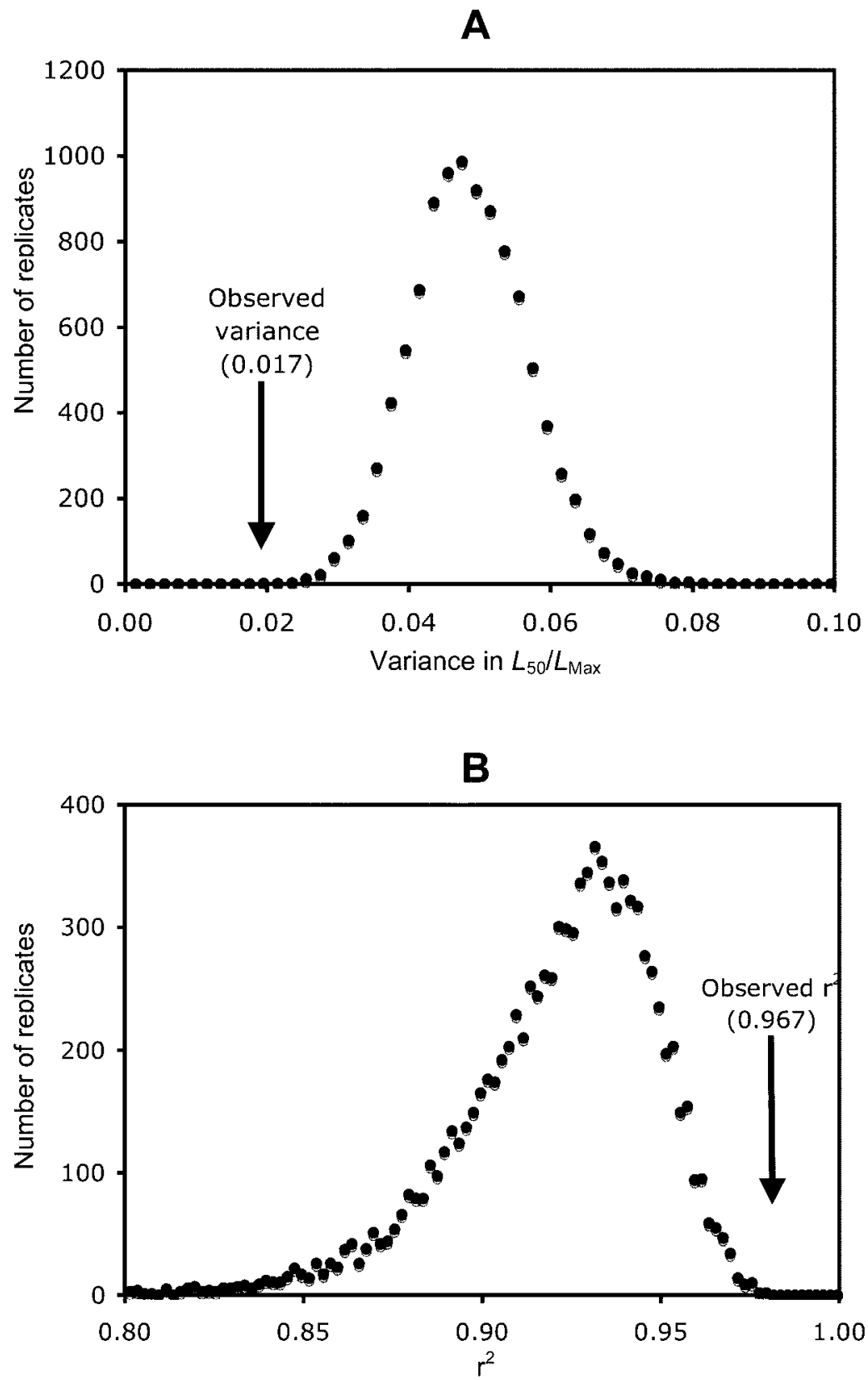

Figure 2: Testing the more appropriate null model: size at maturity $\left(L_{\mathrm{mat}}\right)$ is a uniformly distributed random variable bounded by $\left[0, L_{\max }\right]$, and size at sex change $\left(L_{50}\right)$ is a uniformly distributed random variable bounded by $\left[L_{\operatorname{mat}}, L_{\max }\right]$, where $L_{\max }$ is asymptotic size. The circles denote the distribution of $(A)$ variance in $L_{50} / L_{\max }$ and $(B)$ the $r^{2}$ statistic for the best-fit invariant relative size at sex change for 10,000 replicates of a simulated data set of 77 species of sex changers. The arrow indicates that the variance observed in the real data set $(0.017)$ is significantly lower (estimated $P<.0001)$ and the $r^{2}$ statistic $(0.967)$ significantly higher (estimated $P \approx .01$ ) than predicted by the null model.

at maturity to maximum size (i.e., $L_{\mathrm{mat}} / L_{\max } \approx U[0,1]$, $\left.L_{50} / L_{\max } \approx U\left[L_{\text {mat }} / L_{\max }, 1\right]\right)$. We find that this more appropriate null model predicts significantly more variation in $L_{50} / L_{\max }$ than is observed in the data set and that the $r^{2}$ statistic for the observed data is significantly higher than that predicted by the null model; see figure 2 .

Buston et al. (2004) have criticized this null model on the grounds that maturation at size zero is implausible. 
Table 3: Summary of estimates for the key life-history parameters for the major taxonomic groups containing sex-changing animals

\begin{tabular}{|c|c|c|c|c|}
\hline Taxa & $k / M$ & Source & $\alpha M$ & Source \\
\hline Chordata & .56 & $\begin{array}{l}\text { Charnov 1993; data from Beverton and } \\
\text { Holt 1959, Beverton } 1963\end{array}$ & $\approx 2$ & $\begin{array}{l}\text { Charnov and Berrigan 1990; } \\
\text { data from Beverton and Holt } \\
\text { 1959; Beverton } 1963\end{array}$ \\
\hline Arthropoda & .39 & Charnov 1993; data from Charnov 1979 & $\approx 2$ & Charnov 1979, 1989 \\
\hline Echinodermata & .3 & Charnov 1993; data from Ebert 1975 & No data & Charnov 1993 \\
\hline Annelida & No data & & $1.45-2.5$ & Gemmill et al. 1999 \\
\hline
\end{tabular}

Note: There are no such data for the Mollusca.

They suggest that altering the model so that maturation is bounded by $40 \%$ and $80 \%$ of maximum size is more appropriate, and they find that the associated variance in the relative size at sex change is not significantly different from that observed in the data set at the $5 \%$ level. However, this approach is equally arbitrary and ad hoc. What is the basis for the $40 \%-80 \%$ range, and why are the infinite different possibilities excluded? How much variation is required in the relative size at maturity before $\alpha M$ and $k / M$ are not statistically invariant? What would be a suitable minimum size at maturity? These points are particularly important because a true null model should exclude any related factors, and this is not the case here, because theory predicts that the size at sex change should depend on the size at maturity. Furthermore, invariance is statistical, and so the more appropriate question should be, how much variance could there be in the different param- eters to explain the data? We explore this approach in the next section.

Figure $2 B$ also illustrates an important caveat about $r^{2}$ values in testing for invariant relationships. An $r^{2}$ value gives the amount of variance explained when comparing against the null model of no relationship between the two variables. However, as mentioned above, we expect the mean size at maturity and the mean size at sex change to be positively correlated, because both will be greater in larger species. Indeed, our null model shows that this alone can produce an average $r^{2}$ value of $92.1 \%$ (fig. $2 B$ ). The invariant relative size at sex change hypothesis explains $96.7 \%$ of the variation in the actual data (fig. 1), suggesting that the invariant relationship explains $58.2 \%$ of the variation in the data not explained by our null relationship between size at maturity and sex change $(0.582=$ $[96.7-92.1] /[100-92.1])$. This value is still very large

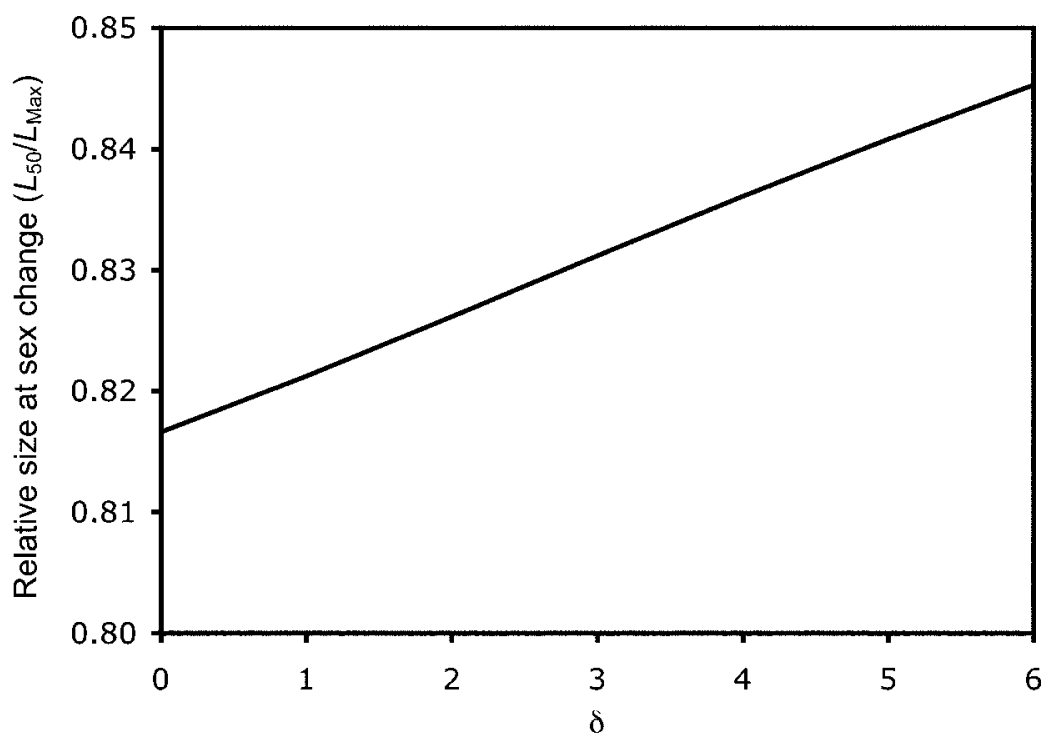

Figure 3: Evolutionarily stable strategy relative size at sex change $\left(L_{50} / L_{\max }\right)$ predicted by the Charnov-Skúladóttir model, assuming the published estimates of $\alpha M \approx 2$ and $k / M \approx 0.6$ and a range of $\delta$. When male fecundity increases with size $(\delta>0)$, the model and published estimates predict a relative size at sex change that is higher than that observed for sex-changing fish $\left(L_{50} / L_{\max }=0.77\right)$. 


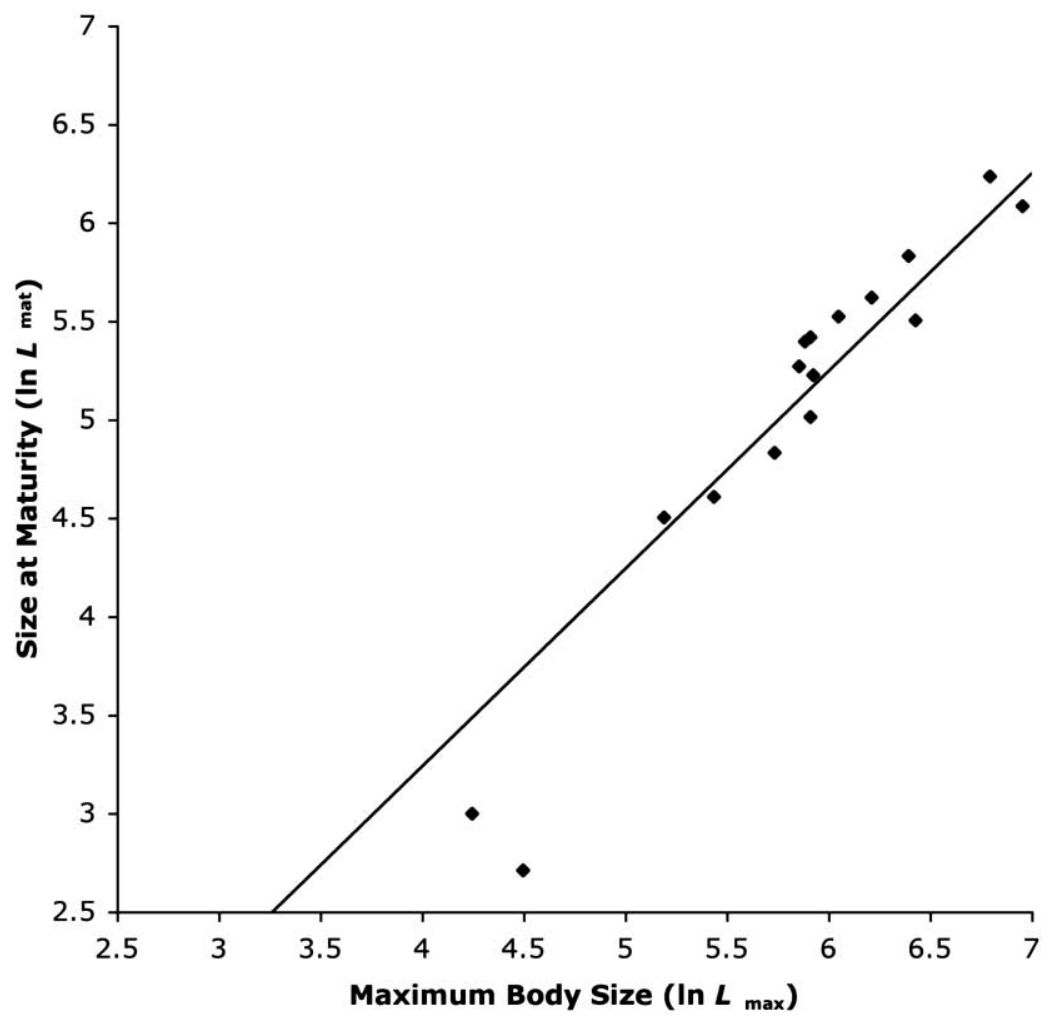

Figure 4: $\log -\log$ plot of $L_{\mathrm{mat}}$ versus $L_{\max }$ for 17 species of sex-changing fish. With the regression slope fixed at 1 , it has an intercept of $-0.78 \pm 0.16$ (95\% confidence interval), $\left(r^{2}=0.90, n=17\right.$ species $)$. The relative size at maturity invariant $\left(L_{\operatorname{mat}} / L_{\max }\right)$ is 0.46 , showing that sexchanging fish mature at approximately $46 \%$ of their maximum body size, on average. Size $\left(L_{\text {mat }}\right.$ and $\left.L_{\text {max }}\right)$ is measured in millimeters before logarithmic transformation.

compared to the average of $2.5 \%-5.4 \%$ from evolutionary and ecological studies (Møller and Jennions 2002).

\section{Sensitivity Analysis: Consequences of Variation in $\alpha M, k / M$, and $\delta$}

Relative size at sex change is invariant $\left(L_{50} / L_{\max } \approx 0.72\right.$; Allsop and West 2004b) over sex-changing animals ranging in size from $2 \mathrm{~mm}$ to $1.5 \mathrm{~m}$. This result is predicted by the Charnov-Skúladóttir model if $\alpha M, k / M$, and $\delta$ are invariant. The value of $\alpha M$ is likely to be invariant across sex-changing species (Charnov 1993; Gemmill et al. 1999), and so Allsop and West's result suggests that $k / M$ and $\delta$ are also invariant or have relatively little influence on the ESS relative size at sex change. To address this requires a sensitivity (elasticity) analysis of the Charnov-Skúladóttir model and an examination of how variation in these lifehistory variables influences the sex change invariant. We will use published values for $\alpha M$ and $k / M$ to obtain an estimate of $\delta$ from the Charnov-Skúladóttir model, given the observed data for sex-changing fish (Allsop and
West 2003b); estimate $\alpha M$ and $k / M$ directly from the sexchanging fish data; and introduce variation into each of the dimensionless quantities $\alpha M, k / M$, and $\delta$ in turn, to see how much variation in each corresponds to the observed variation in $L_{50} / L_{\max }$. We restrict our attention to fish only, since there are many more data on the relevant life-history variables for them than for other sex changers. In this subset of the data, the best-fit invariant timing of sex change is $77 \%$ of maximum body size.

\section{Variation in $\delta$}

Assuming $\alpha M \approx 2$ (Charnov and Berrigan 1990, 1991; Charnov 1993) and $k / M \approx 0.6$ (Charnov 1993; see table 3 for a summary of estimates for $\alpha M$ and $k / M$ ), the optimal relative age (and hence size) at sex change can be determined numerically from equation (12), given a value for $\delta$. We do this for a range of $\delta$ in figure 3. These results predict that the relative size at sex change $\left(L_{50} / L_{\max }\right)$ is an increasing function of the male fitness exponent $(\delta)$ and that the slope of this relation is very small. The weak 


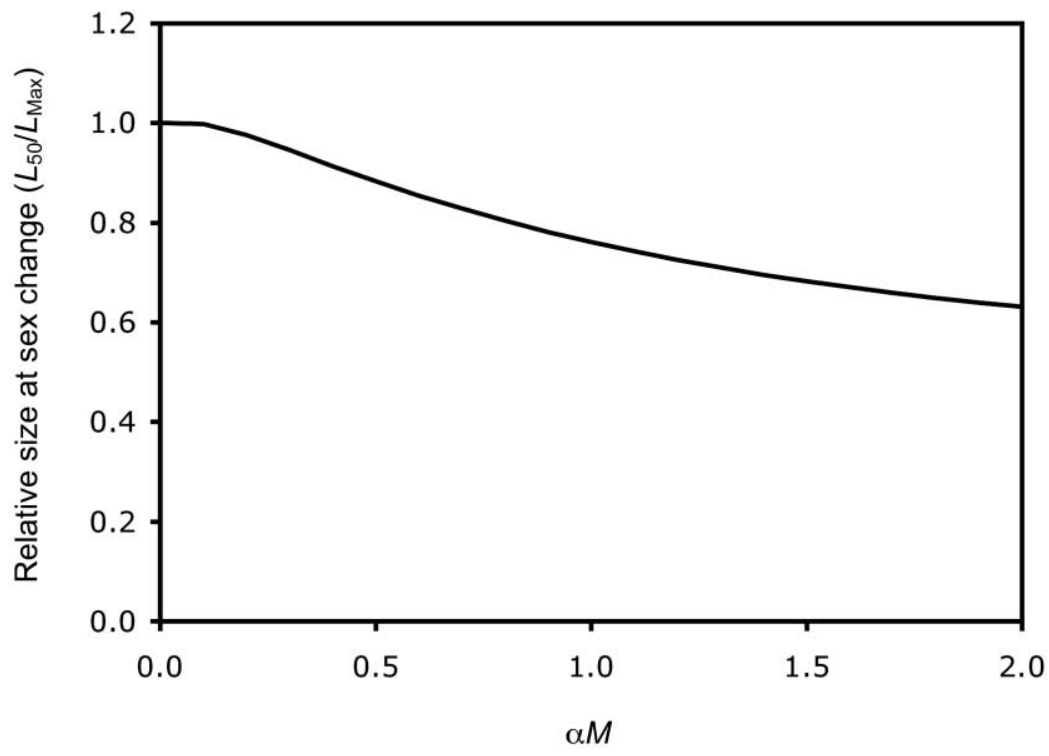

Figure 5: Evolutionarily stable strategy relative size at sex change $\left(L_{50} / L_{\max }\right)$ predicted by the Charnov-Skúladóttir model assuming that $\delta \approx 3$ and $\alpha M \times k / M=\alpha k=0.616$, as estimated from the size at maturity data. By plotting for a range of $\alpha M$ to see where the model predicts the observed size at sex change invariant $\left(L_{50} / L_{\max }=0.77\right)$, we can obtain an estimate of $\alpha M$ and hence $k / M$.

relationship between the male fitness exponent and the timing of sex change suggests that the former need not be particularly invariant in order for latter to show great invariance. In addition, the predicted relative size at sex change is much greater than that observed in sex-changing fish, a point addressed below.

The positive relation between the male fecundity exponent and the relative timing of sex change can be explained as follows. For protandrous species $(\delta<3)$, an increase in $\delta$ means that the relative success of small males is reduced, and so the individual is selected to increase reproduction as a male in order to make up this quota of total reproduction; hence, longer time is spent as the first sex. Conversely, for protogynous species $(\delta>3)$, an increase in $\delta$ means that the relative fitness of the large males is increased, so that less time need be spent reproducing as a male, and hence the individual spends longer reproducing as the first sex. In both instances, an increase in $\delta$ is associated with delayed sex change. With regard to this prediction that the relative size at sex change should increase weakly with $\delta$, the data do reveal a slight tendency for protogynous fish $\left(\delta>3, \mathrm{E}\left[L_{50} / L_{\max }\right]=0.79\right)$ to have a higher relative size at sex change than protandrous fish $\left(\delta<3, \mathrm{E}\left[L_{50} / L_{\max }\right]=0.74\right)$. However, as might be expected, given the weak predicted effect, this difference is not significant $(P=.21)$.

The results given in figure 3 also predict that the relative size at sex change is too high to explain the empirical observation $L_{50} / L_{\max }=0.77$ for sex-changing fish. This suggests either that the model is incorrect or that the values of $\alpha M$ and $k / M$ published for fish in general do not correspond to those in our data set. We investigate this possibility using the data sets compiled by Allsop and West $(2003 a, 2003 b)$ and find support for the suggestion that sex-changing fish may have $\alpha M$ and/or $k / M$ values different from those published for other species. The product $\alpha k$ determines the relative size at maturity $\left(L_{\operatorname{mat}} / L_{\max }=\right.$ $1-\exp [-\alpha k]$ ), so we may use size at maturity data (table A1 in the online edition of the American Naturalist) to estimate $\alpha k$. Assuming an invariant relative size at maturity (i.e., a slope of unity on a plot of $\log L_{\text {mat }}$ vs. $\log L_{\max } ;$ fig. 4$)$, we find that the least squares regression gives $L_{\text {mat }} / L_{\max } \approx 0.46$ and hence $\alpha k \approx 0.62$. This value is approximately half of that published for other fish $(\alpha M \times k / M=\alpha k \approx 1.2)$, indicating that sex-changing fish mature relatively earlier than other fish. There is a danger associated with the use of von Bertalanffy's equation in relation to size at maturity. Since immature organisms do not reproduce and hence may allocate more of their resources to growth, the growth rate coefficient (k) may be somewhat higher prematuration than postmaturation (Day and Taylor 1997). However, the associated bias in the estimation of the postmaturation growth rate from age at maturity data is in the wrong direction to explain the discrepancy between the estimated $\alpha k$ and that published for fish in general. In the next section, we show that this reduced estimate of $\alpha k$ is more consistent with the observed timing of sex change. 
A

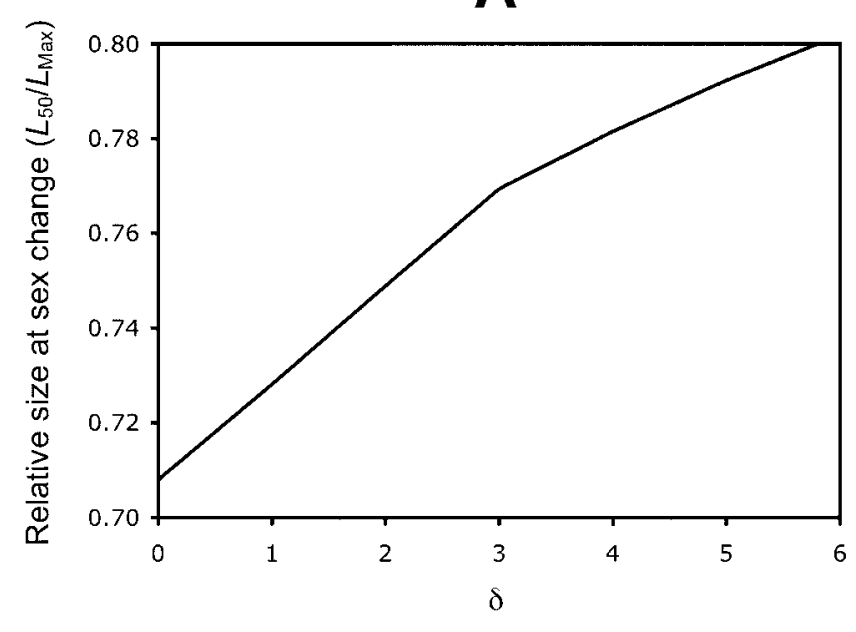

C

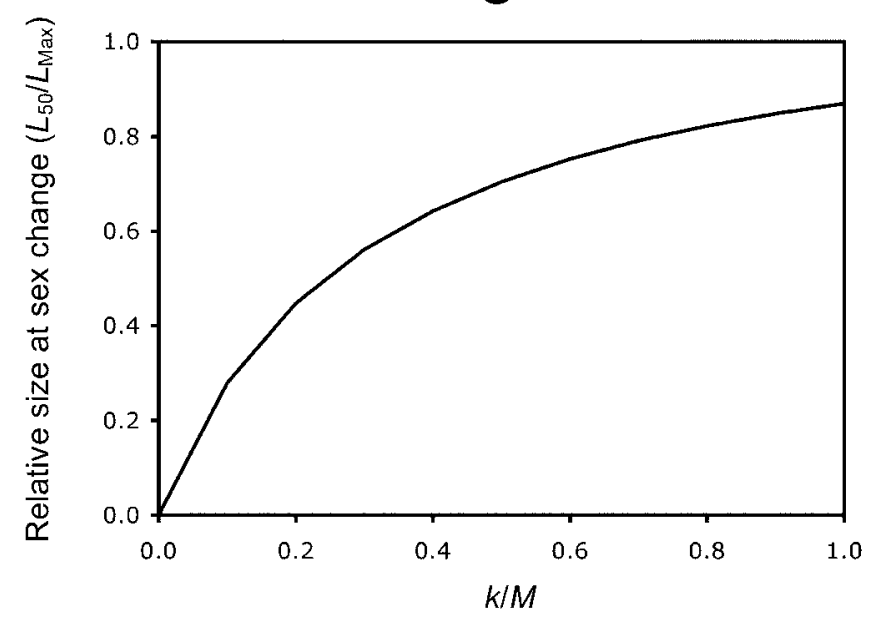

B

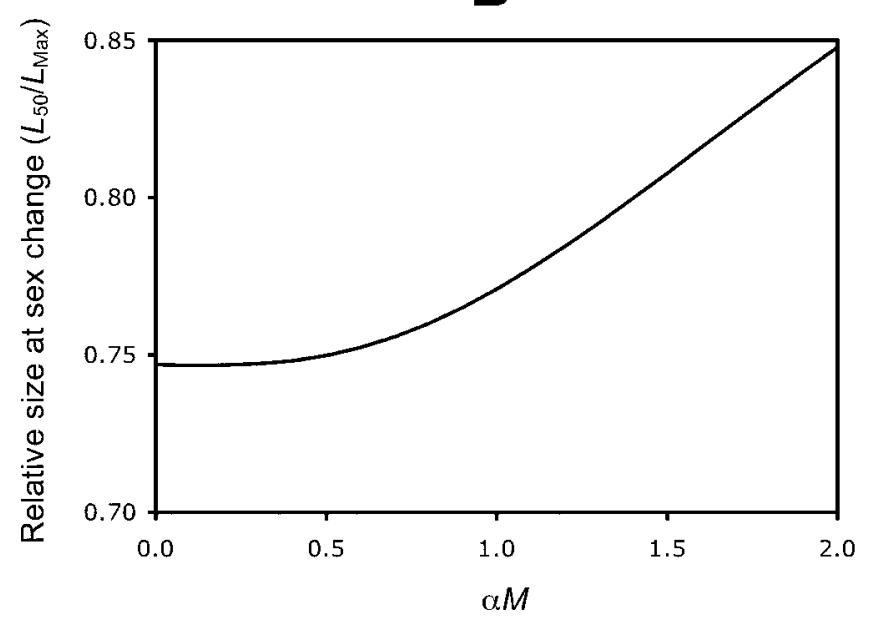

D

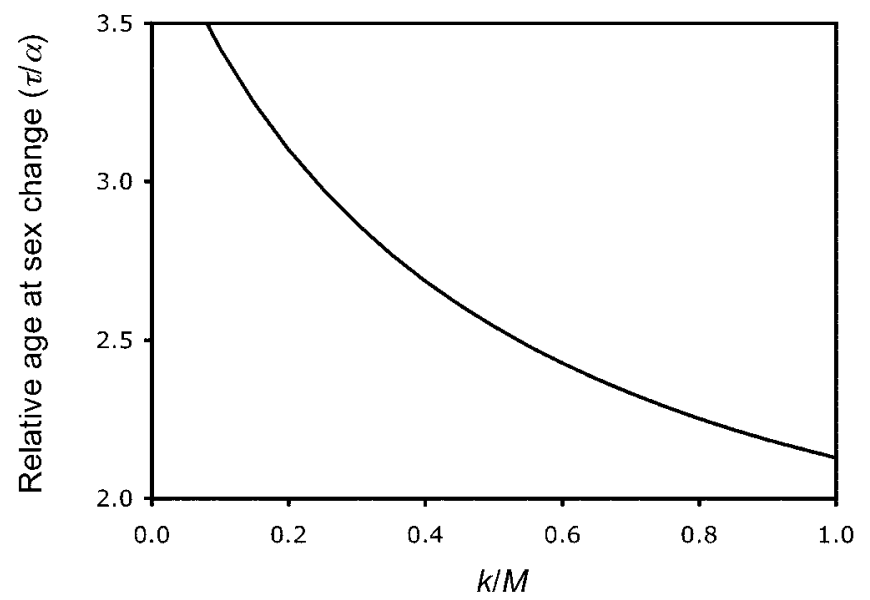

Figure 6: Effect of variation in the three dimensionless quantities of interest on variation in the evolutionarily stable strategy (ESS) relative size of sex change $\left(L_{50} / L_{\max }\right)$, as predicted by the model of Charnov and Skúladóttir (2000), with $\alpha M \approx 0.96, k / M \approx 0.64$, and $\delta \approx 3$. In $A, \alpha M$ and $k / M$ are held fixed at their estimates, and $\delta$ is varied. In $B, \delta$ and $k / M$ are held fixed at their estimates, and $\alpha M$ is varied. In $C, \delta$ and $\alpha M$ are held fixed at their estimates, and $k / M$ is varied. In $D$, the relationship between $k / M$ and the ESS relative age at sex change $\left(\tau^{*} / \alpha\right)$ is investigated, with $\delta$ and $\alpha M$ held constant. 


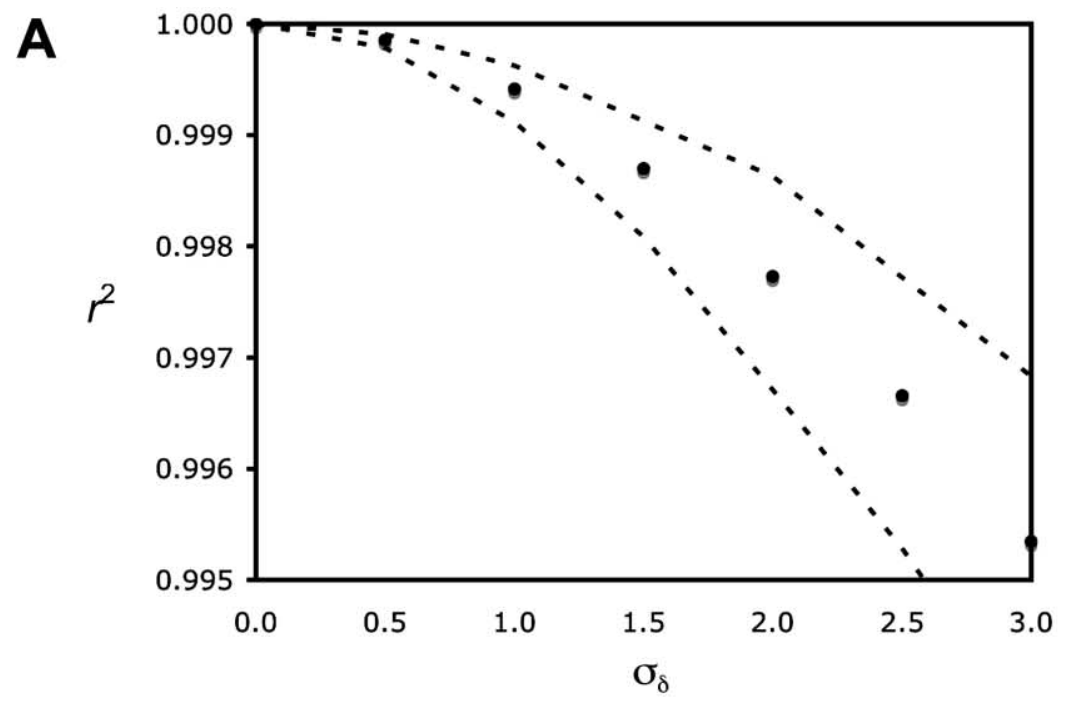

B

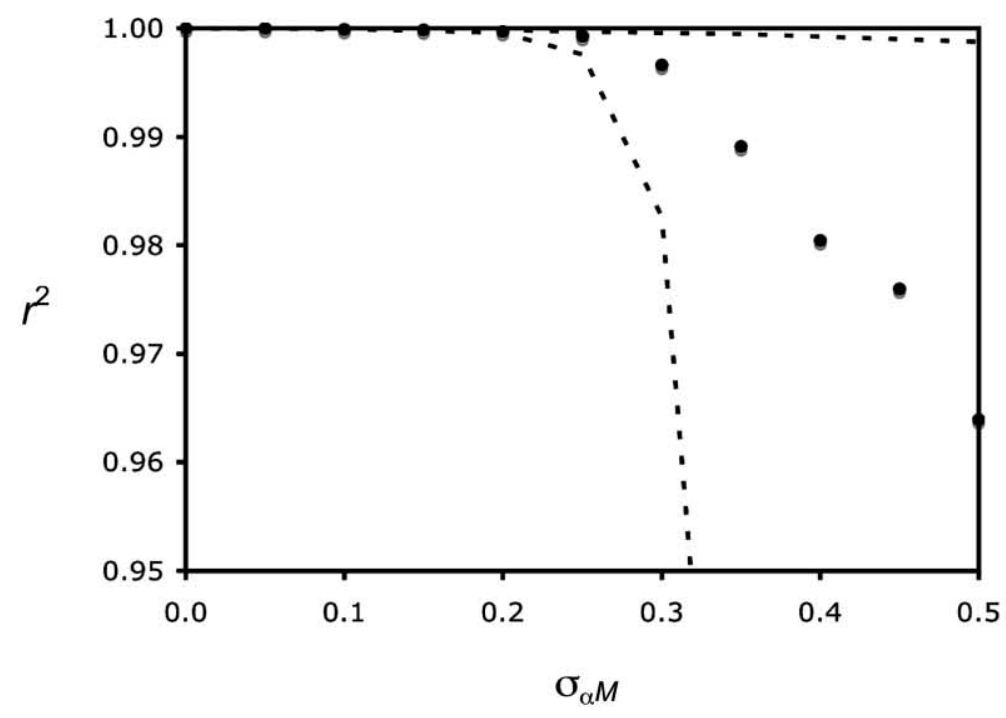

C

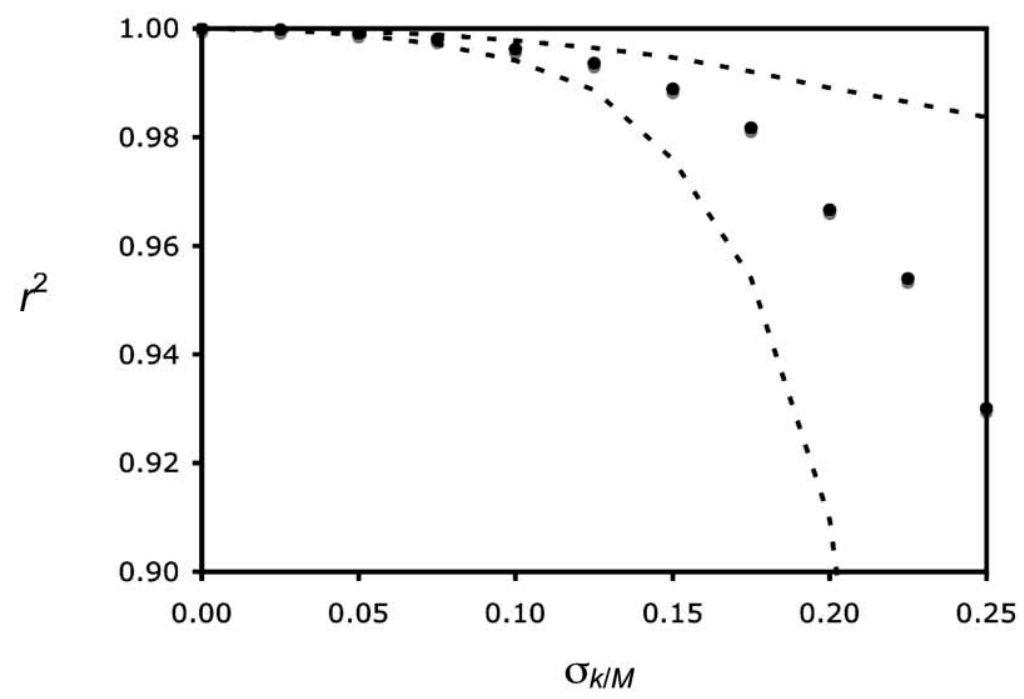




\section{Estimating $\alpha M$ and $k / M$}

We now estimate values for $\alpha M$ and $k / M$ for sex-changing fish. As outlined above, we can numerically solve equation (12) to give a relative age (and hence size) at sex change, given values for $\delta, \alpha M$, and $k / M$. By exploring a range of these three parameters, we can determine which triplets give the observed $L_{50} / L_{\max }=0.77$. As we have seen, the male fitness exponent $(\delta)$ has very little effect on the relative size at sex change-we can essentially ignore this parameter and restrict our attention to the two parameters $\alpha M$ and $k / M$. Recalling that some species in the data set will have $\delta<3$ while others have $\delta>3$ (since there is a mixture of protandry and protogyny), we assume $\delta \approx 3$ for the purposes of estimating the other two life-history parameters. We estimated that the invariant product of $\alpha M$ and $k / M$ is approximately 0.62 , and so the parameter set is effectively reduced to a single quantity: given $\alpha M$, $k / M$ will be given by $0.62 / \alpha M$. In figure 5 , we determine the effect on the relative size at sex change of variation in $\alpha M$ by allowing it to take a range of values while satisfying the estimate of $\alpha k=0.62$. We find that the model predicts the observed invariant relative size at sex change $\left(L_{50} / L_{\max }=0.77\right)$ when $\alpha M \approx 0.96$. From this, we also estimate $k / M$ to be $\alpha k / \alpha M \approx 0.64$.

\section{Assessing Variation in $\delta, \alpha M$, and $k / M$}

We have obtained estimates for the average values of $\delta$, $\alpha M$, and $k / M$ in sex-changing fish. We now make a qualitative assessment of how variation in these life-history parameters translates into variation in the relative size at sex change by varying the value of each parameter in turn while holding the other two constant (at their estimated values: $\delta=3, \alpha M=0.96, k / M=0.64)$. Our results are given in figure 6 . As above, we find that the value of the male fitness exponent $(\delta)$ has little effect on the relative size at sex change (fig. 6A), while variation in $\alpha M$ (fig. $6 B$ ) and especially $k / M$ (fig. 6C) have a more dramatic effect.

We find that the value of $\alpha M$ correlates positively with the relative size at sex change (fig. $6 B$ ) when the values of $k / M$ and $\delta$ are held constant. One way to visualize this is to hold $k, M$, and $\delta$ fixed and to vary age at maturity, $\alpha$.
It makes sense for species that mature later to change sex later in order to make up their quota of reproduction as the first sex. Species with a higher $\alpha M$ should therefore tend to change sex at a greater size. We have also found that increasing $k / M$ increases the relative size at sex change (fig. 6C) when $\alpha M$ and $\delta$ are held constant. To see why, hold $\alpha, M$, and $\delta$ constant, and allow $k$ to vary. As the von Bertalanffy growth coefficient is increased, the size at all ages is increased, and so if we assume no effect on the ESS relative age at sex change $\left(\tau^{*} / \alpha\right)$, we would expect an increased relative size at sex change $\left(L_{50} / L_{\text {max }}\right)$. In fact, the ESS relative age at sex change is a decreasing function of $k$ (fig. 6D). This is because the increase in size due to increased $k$ is more pronounced at earlier ages; hence, the reproduction of the first sex is improved the most by this increase, so that less time need be spent reproducing as that sex. This means that in increasing $k$ the ESS age at sex change is reduced, but the size at that age is increased. The net effect is a positive correlation between $k / M$ and the relative size at sex change.

A more quantitative approach is to use the model to simulate sex change data for a range of variation in the underlying dimensionless quantities, to see how much variation corresponds to that observed in the real data set. We simulate 52 species of sex-changing fish (as in the actual data set), each assigned values for $\alpha M, k / M$, and $\delta$. Within each data set, two of these dimensionless quantities are held fixed at their estimates from the previous section, while the other takes a pseudorandom value independently drawn for each species from the normal distribution with mean given by the estimated value and standard deviation $\sigma$. Because it is biologically implausible for $\alpha M$ and $k / M$ to take negative values, we draw these from a normal distribution truncated at the origin, which, for the parameters we will explore, involves removing a trivial proportion $(<3 \%)$ of the probability distribution. With the actual data on maximum size $\left(L_{\max }\right)$, the Charnov-Skúladóttir model of sex change is then used to generate the ESS relative size $\left(L_{50} / L_{\max }\right)$ at sex change for each of the simulated fish species. For each data set, an $r^{2}$ statistic can be generated to describe how well the simulated data conform to the prediction of a slope of unity in a plot of $\log L_{50}$ against $\log L_{\max }$. This procedure is used to explore a range

Figure 7: Sensitivity analysis of the Charnov-Skúladóttir model. Two of the three dimensionless quantities of interest are held fixed at their estimates $(\alpha M=0.96, k / M=0.64, \delta \approx 3$ ) while the third is drawn from a normal distribution with mean given by the above estimate and standard deviation $\sigma$, to generate size at sex change data for 52 species of fish. The $r^{2}$ statistic relating the data to the best-fit invariant (i.e., having a slope of unity in a plot of $\log L_{50}$ versus $\log L_{\max }$, where $L_{50}$ and $L_{\max }$ are the size at sex change and asymptotic size, respectively) is determined for each value of $\sigma$ and each of the three dimensionless quantities in turn. $A$, Mean $r^{2}$ for 200 replicates over a range of $\delta$ (holding $\alpha M$ and $k / M$ fixed), with the dashed lines indicating the zone in which $95 \%$ of the replicates fell. $B$, Mean $r^{2}$ for 200 replicates over a range of $\alpha M$ (holding $\delta$ and $k / M$ fixed), with the dashed lines indicating the zone in which $95 \%$ of the replicates fell. $C$, Mean $r^{2}$ for 200 replicates over a range of $k / M$ (holding $\delta$ and $\alpha M$ fixed), with the dashed lines indicating the zone in which $95 \%$ of the replicates fell. 
of variation (standard deviation $\sigma$ ) in each of the invariant quantities $\alpha M, k / M$, and $\delta$.

From figure 7, we can read off the estimate of the standard deviation for each of the life-history parameters by seeing what value of $\sigma$ corresponds to the observed $r^{2}=0.973$. Figure $7 A$ confirms that the invariant relative size at sex change is expected to hold even with extensive variance in the male fitness exponent $(\delta)$ when the other life-history parameters do not vary. Figure $7 B$ reveals that variation in $\alpha M$ corresponding to a standard deviation of around 0.45 (47\% of the estimated mean, $\mathrm{E}[\alpha M]=$ $0.96)$ can account for the observed variation in the relative size at sex change. Figure $7 C$ reveals that a standard deviation in $k / M$ of around 0.18 (28\% of the estimated mean, $\mathrm{E}[k / M]=0.64)$ can account for the observed variation in $L_{50} / L_{\max }$. It should be noted that these results are upper limits on the amount of variation, because they assume that only one parameter is variable, whereas in reality there will be some variation in each.

\section{Discussion}

We have formally derived the life-history invariants predicted by Charnov and Skúladóttir (2000), who modeled sex change conditional on an individual's size (and hence age). These are invariant: relative age at sex change $(\tau / \alpha)$, relative size at sex change $\left(L_{50} / L_{\max }\right)$, and breeding sex ratio $\left(N_{1} / N_{2}\right)$. Previously, Buckingham's (1914) $\pi$ theorem was invoked in order to show that the appropriate fitness function could be expressed in terms of dimensionless quantities. We employed a simple "switching variables" technique to explicitly derive this fitness function. In addition, we have shown that these invariants can be predicted with a different approach, when sex change is assumed to occur in response to social cues.

Allsop and West $(2003 a, 2003 b)$ showed invariance in the relative size at sex change across all sex-changing organisms for which there are data and in the relative age at sex change in fish. These results were criticized by Buston et al. (2004), who argued that randomization tests should be used instead of standard methodology (Harvey and Pagel 1991; Charnov 1993; Brown et al. 2000). We have argued that their randomization test was not truly null, that the data do not fit their model, and that more appropriate tests support the invariance conclusion. Furthermore, we suggest a more powerful approach: we avoid randomization tests based on possibly arbitrary assumptions and instead examine how much variance in the different parameters would explain the observed data.

We carried out a numerical sensitivity analysis in order to determine the relative consequences of variation in the dimensionless parameters that can influence the relative size at sex change. These results showed that the invariant prediction depends primarily on invariance in $\alpha M$ and $k /$ $M$ and that variation in $\delta$ has little consequence for the ESS size at sex change. This result illustrates clearly one of the major problems with the Buston et al. "null" model - it was not null, because it effectively assumed an invariant $\alpha M$ and $k / M$ and allowed only $\delta$ to vary, and so we would expect it to predict the observed data.

How much variation in $\alpha M$ and $k / M$ are consistent with the observed data on relative size at sex change? We estimated the variation in each of these parameters that is consistent with the observed variation in the timing of sex change in the fish data set. We found that $\alpha M \approx 0.96$ (with a standard deviation of \pm 0.45$)$ and $k / M \approx 0.64 \pm 0.18$. This suggests that there can be a relatively large amount of variation in $\alpha M$ but less in $k / M$. These results are upper limits on the amount of variation, because they assume that only one parameter is variable, whereas in reality there will be some variation in each. More generally, the invariant result suggests a fundamental similarity across all animals in the underlying forces that select for sex change (Allsop and West 2003a). Our results suggest that the fundamental similarities are the basic assumptions of the Charnov-Skúladóttir model and the value of $k / M$ and, to a lesser extent, $\alpha M$.

Our results also lead to the prediction that the value of $\alpha M$ differs in sex-changing fish from that in other fish species. Specifically, the published values for fish in general give $\alpha M \approx 2$ and $k / M \approx 0.6$. In contrast, we predict that $\alpha M \approx 1$ for sex-changing species. We have verified this prediction by estimating the product of these two putative invariants from the relative size at maturity data in sexchanging fish, confirming that $\alpha M \times k / M=\alpha k \approx 0.6$, half of the value expected for fish in general. More investigation, both theoretical and empirical, is needed to explain this difference between sex changers and other fish.

We conclude with two general points. First, the debate over the usefulness of applying the life-history invariant approach to sex change cuts to the heart of the philosophy of statistics in the biological sciences. Because we are dealing with biology, it is clear that there are really no true invariants in the physical sense. However, there are a number of statistically invariant relationships that hold across taxa for reasons that are not immediately apparent, and these require explanation. Second, we have demonstrated that invariant theory can be used to estimate the values of and variation in important biological parameters. This is especially useful when it allows us to get at parameters that are difficult or laborious to measure directly. Another much-studied example of this is the use of sex ratios and sex ratio theory to estimate inbreeding rates in protozoan parasites (Read et al. 1992; West et al. 2001; Nee et al. 2002). 


\section{Acknowledgments}

We thank J. Banavar, N. Barton, P. Buston, T. Day, E. Leigh, P. Munday, J. Taylor, and R. Warner for comments and discussion, and in particular we thank an anonymous reviewer, whose careful and detailed comments significantly improved the manuscript. S. Williamson helped to produce the figures. Funding was provided by the Biotechnology and Biological Sciences Research Council, the Natural Environment Research Council, the Royal Society, Leverhulme Trust, and Royal Commission for the Exhibition of 1851 .

\section{Literature Cited}

Allsop, D. J., and S. A. West. 2003a. Changing sex at the same relative body size. Nature 425:783-784.

- 2003b. Constant relative age and size at sex change in sequentially hermaphroditic fish. Journal of Evolutionary Biology 16:921-929.

- 2004a. Evolutionary biology: sex change and relative body size in animals (reply). Nature 428, doi:10.1038/nature2513.

- 2004b. Sex-ratio evolution in sex changing animals. Evolution 58:1019-1027.

- 2004c. Sex allocation in the sex-changing marine goby Coryphopterus personatus on atoll fringing reefs. Evolutionary Ecology Research 6:843-855.

Beverton, R. J. H. 1963. Maturation, growth and mortality of clepeid and engraulid stocks in relation to fishing. Rapports et ProcèsVerbaux des Reunions Conseil International pour l'Exploration de la Mer 154:44-67.

1992. Patterns of reproductive strategy parameters in some marine teleost fishes. Journal of Fish Biology 41:137-160.

Beverton, R. J. H., and S. J. Holt. 1959. A review of lifespans and mortality rates of fishes in nature, and their relation to growth and other physiological characteristics. Pages 142-180 in C. E. W. Wolstenholme and M. O'Connor, eds. Ciba Foundation Colloquia on Aging. Vol 5. J. \& A. Churchill, London.

Brown, J. H., G. B. West, and B. J. Enquist. 2000. Scaling in biology: patterns and processes, causes and consequences. Pages 1-24 in J. H. Brown and G. B. West, eds. Scaling in biology. Oxford University Press, Oxford.

Brule, T., C. Deniel, T. Colas-Marrufo, and M. Sanchez-Crespo. 1999. Red grouper reproduction in the southern Gulf of Mexico. Transactions of the American Fisheries Society 128:385-402.

Buckingham, E. 1914. On physically similar systems: illustrations of the use of dimensional equations. Physical Review 4:345-376.

Buston, P. M., P. L. Munday, and R. R. Warner. 2004. Evolutionary biology: sex change and relative body size in animals. Nature 428 , doi:10.1038/nature2512.

Charnov, E. L. 1979. The genetical evolution of patterns of sexuality: Darwinian fitness. American Naturalist 113:465-480.

1982a. Alternative life-histories in protogynous fishes: a general evolutionary theory. Marine Ecology Progress Series 9:305307.

. 1982b. The theory of sex allocation. Princeton University Press, Princeton, NJ.

- 1989. Evolution of the breeding sex-ratio under partial sex change. Evolution 43:1559-1561.
1993. Life history invariants. Oxford University Press, Oxford.

Charnov, E. L., and D. Berrigan. 1990. Dimensionless numbers and life history evolution: age of maturity versus the adult lifespan. Evolutionary Ecology 4:273-275.

. 1991. Dimensionless numbers and the assembly rules for life histories. Philosophical Transactions of the Royal Society of London B 332:41-48.

Charnov, E. L., and U. Skúladóttir. 2000. Dimensionless invariants for the optimal size (age) of sex change. Evolutionary Ecology Research 2:1067-1071.

Charnov, E. L., D. Gotshall, and J. Robinson. 1978. Sex ratio: adaptive response to population fluctuations in pandalid shrimp. Science 200:204-205.

Christiansen, F. B. 1991. On the conditions for evolutionary stability for a continuously varying character. American Naturalist 138:3750 .

Crabtree, R. E., and L. H. Bullock. 1998. Age, growth, and reproduction of black grouper, Mycteroperca bonaci, in Florida waters. Fishery Bulletin 96:735-753.

Day, T., and P. D. Taylor. 1997. Von Bertalanffy's growth equation should not be used to model age and size at maturity. American Naturalist 149:381-393.

de Valpine, P. 2000. A new demographic function maximized by lifehistory evolution. Proceedings of the Royal Society of London B 267:357-362.

Ebert, T. A. 1975. Growth and mortality of post-larval echinoids. American Zoologist 15:755-775.

Ferreira, B. P., and G. R. Russ. 1995. Population-structure of the leopard coralgrouper, Plectropomus leopardus, on fished and unfished reefs off Townsville, central Great Barrier Reef, Australia. Fishery Bulletin 93:629-642.

Fisher, R. A. 1930. The genetical theory of natural selection. Oxford University Press, Oxford.

Gemmill, A. W., A. Skorping, and A. F. Read. 1999. Optimal timing of first reproduction in parasitic nematodes. Journal of Evolutionary Biology 12:1148-1156.

Ghiselin, M. T. 1969. The evolution of hermaphroditism amongst animals. Quarterly Review of Biology 44:189-208.

Gillanders, B. M. 1995. Reproductive biology of the protogynous hermaphrodite Achoerodus viridis (Labridae) from southeastern Australia. Marine and Freshwater Research 46:999-1008.

Grandcourt, E. M. 2002. Demographic characteristics of a selection of exploited reef fish from the Seychelles: preliminary study. Marine and Freshwater Research 53:123-130.

Harvey, P. H., and M. D. Pagel. 1991. The comparative method in evolutionary biology. Oxford University Press, Oxford.

Leigh, E. G., E. L. Charnov, and R. R. Warner. 1976. Sex ratio, sex change and natural selection. Proceedings of the National Academy of Sciences of the USA 73:3656-3660.

Lorenzo, J. M., J. G. Pajuelo, M. Mendez-Villamil, J. Coca, and A. G. Ramos. 2002. Age, growth, reproduction and mortality of the striped seabream, Lithognathus mormyrus (Pisces, Sparidae), off the Canary Islands (central-east Atlantic). Journal of Applied Ichthyology 18:204-209.

MacArthur, R. H. 1965. Ecological consequences of natural selection. Pages 388-397 in T. H. Waterman and H. Morowitz, eds. Theoretical and mathematical biology. Blaisdell, New York.

Mackie, M. 2000. Reproductive biology of the halfmoon grouper, 
Epinephelus rivulatus, at Ningaloo Reef, Western Australia. Environmental Biology of Fishes 57:363-376.

Marino, G., E. Azzurro, A. Massari, M. G. Finoia, and A. Mandich. 2001. Reproduction in the dusky grouper from the southern Mediterranean. Journal of Fish Biology 58:909-927.

Maynard Smith, J., and G. R. Price. 1973. The logic of animal conflict. Nature 246:15-18.

Millius, S. 2004. When to change sex. Science News 165:40-41.

Møller, A., and M. Jennions. 2002. How much variance can be explained by ecologists and evolutionary biologists? Oecologia (Berlin) 132:492-500.

Nakashima, Y., T. Kuwamura, and Y. Yogo. 1995. Why be a bothways sex changer? Ethology 101:301-307.

Nee, S., S. A. West, and A. F. Read. 2002. Inbreeding and parasite sex ratios. Proceedings of the Royal Society of London B 269:755760.

Pauly, D. 1980. On the inter-relationships between natural mortality, growth parameters, and mean environmental temperature in 175 fish stocks. Journal du Conseil International pour l'Exploration de la Mer 39:175-192.

Policansky, D. 1982. Sex change in plants and animals. Annual Review of Ecology and Systematics 13:471-495.

Read, A. F., A. Narara, S. Nee, A. E. Keymer, and K. Day. 1992. Gametocyte sex ratios as an indirect measure of outcrossing rates in malaria. Parasitology 104:387-395.

Robertson, D. R. 1972. Social control of sex reversal in a coral reef fish. Science 177:1007-1009.

Robertson, D. R., and J. H. Choat. 1974. Protogynous hermaphroditism and social systems in labrid fish. Pages 217-225 in Proceedings of the Second International Symposium on Coral Reefs. Vol. 1. Great Barrier Reef Committee, Brisbane.

Robertson, D. R., and R. R. Warner. 1978. Sexual patterns in the labroid fishes of the western Carribbean. II. The parrotfishes (Scaridae). Smithsonian Contributions to Zoology 255:1-26.

Scharer, L., and D. B. Vizoso. 2003. Earlier sex change in infected individuals of the protogynous reef fish Thalassoma bifasciatum. Behavioral Ecology and Sociobiology 55:137-143.

Shapiro, D. Y. 1980. Role of females in the initiation of sex change in a coral-reef fish. American Zoologist 20:826-826.

- 1981. Size, maturation and the social control of sex reversal in the coral reef fish Anthias squamipinnis (Peters). Journal of Zoology (London) 193:105-128.

Shapiro, D. Y., and R. Lubbock. 1980. Group sex ratio and sex reversal. Journal of Theoretical Biology 82:411-426.

Shaw, R. F., and J. D. Mohler. 1953. The selective significance of the sex ratio. American Naturalist 87:337-342.

Skúladóttir, U., and G. Petursson. 1999. Defining populations of northern shrimp, Pandalus borealis (Kroyer 1938), in Icelandic waters using maximum length and maturity ogive of females. Rit Fiskideildar 16:247-262.

Stephens, D. W., and S. R. Dunbar. 1993. Dimensional analysis in behavioural ecology. Behavioural Ecology 4:172-183.

Tobin, A. J., M. J. Sheaves, and B. W. Molony. 1997. Evidence of protandrous hermaphroditism in the tropical sparid Acanthopagrus berda. Journal of Fish Biology 50:22-33.

Villamil, M. M., J. M. Lorenzo, J. G. Pajuelo, A. G. Ramos, and J. Coca. 2002. Aspects of the life history of the salema, Sarpa salpa (Pisces, Sparidae), off the Canarian Archipelago (central-east Atlantic). Environmental Biology of Fishes 63:183-192.

von Bertalanffy, L. 1938. A quantitative theory of organic growth. Human Biology 10:181-213.

Warner, R. R. 1984. Mating behavior and hermaphroditism in coral reef fishes. American Scientist 72:128-136.

1988a. Sex change and the size-advantage model. Trends in Ecology \& Evolution 3:133-136.

. 1988b. Sex change in fishes: hypotheses, evidence, and objections. Environmental Biology of Fishes 22:81-90.

Warner, R. R., and D. R. Robertson. 1978. Sexual patterns in the labroid fishes of the western Carribbean. I. The wrasses (Labridae). Smithsonian Contributions to Zoology 254:1-27.

Warner, R. R., and S. E. Swearer. 1991. Social control of sex change in the bluehead wrasse, Thalassoma bifasciatum (Pisces: Labridae). Biological Bulletin 181:199-204.

Warner, R. R., D. R. Robertson, and E. G. Leigh. 1975. Sex change and sexual selection: the reproductive biology of a labrid fish is used to illuminate a theory of sex change. Science 190:633-638.

West, S. A., S. E. Reece, and A. F. Read. 2001. The evolution of gametocyte sex ratios in malaria and related apicomplexan (protozoan) parasites. Trends in Parasitology 17:525-531.

Editor: Jonathan B. Losos Associate Editor: Peter D. Taylor 